\title{
From bone to breast and back - the bone cytokine RANKL and breast cancer
}

\author{
Lorenz C Hofbauer ${ }^{* 1,2}$, Tilman D Rachner' and Christine Hamann³
}

\begin{abstract}
Receptor activator of nuclear factor-KB ligand (RANKL) plays a pivotal role in regulating bone homeostasis. Osteoporosis and malignant bone disease secondary to breast cancer are characterized by enhanced RANKL production and increased bone turnover. Thus, denosumab, a monoclonal antibody to RANKL, has been developed and is now approved for various bone loss conditions. Recent results indicate that RANKL may also promote the development and osseous migration of breast cancer.
\end{abstract}

Breast cancer and osteoporotic fractures affect one in eight and one in three women, respectively, during lifetime, ranking these two diseases high on the women's health agenda. In recent years, screening programs have been established and efficient therapies for the treatment of both diseases have become available. Hormone replacement therapy is effective against bone loss in postmenopausal osteoporosis, but is associated with increased incidence of breast cancer. By contrast, some therapies against osteoporosis may protect against breast cancer, including raloxifene [1] and bisphosphonates [2,3].

There may be even closer links between these two disorders at the molecular level, involving the receptor activator of nuclear factor- $\mathrm{kB}$ ligand (RANKL). Its major role in human physiology is to control the differentiation and activation of osteoclasts, the bone cells specialized to break down bone [4]. Osteoclasts initiate a sequence of events whereby bone of poor quality is removed and replaced by new bone. This remodeling process constantly repairs the skeleton. The delicate balance between resorption and formation of bone can be severely

\footnotetext{
${ }^{*}$ Correspondence: lorenz.hofbauer@uniklinikum-dresden.de

'Division of Endocrinology, Diabetes, and Bone Diseases, Department of Medicine III, Dresden Technical University Medical Center, Fetscherstr. 74, D-01307 Dresden, Germany

Full list of author information is available at the end of the article
}

impaired by declining sex steroid hormones, as in menopause, or during adjuvant therapy for breast or prostate cancer [5]. At the cellular level, up-regulation of RANKL promotes osteoclast differentiation and activity, induces excessive bone resorption, and leads to osteoporotic fractures. This common theme applies to several important bone loss disorders, including postmenopausal osteoporosis and osteoporosis associated with aromatase inhibitor and androgen-ablative therapy, osteolytic metastases, myeloma bone disease, and giant cell tumors of the bone [5]. Based on its fundamental role in skeletal homeostasis, RANKL has become a therapeutic target in the treatment of bone disorders, and a monoclonal antibody against RANKL, denosumab, has been approved for the treatment of postmenopausal osteoporosis [6].

Since its discovery, the RANKL/RANK pathway has been implicated in the modulation of several extraskeletal processes, including development of the immune system, vascular biology, skin homeostasis, central control of body temperature, and breast development. For instance, mice that were deficient of RANK, the receptor of RANKL, did not develop a lactating mammary gland, and their offspring died as a result of starvation [7]. The dual role of RANKL/RANK in releasing calcium and other minerals from bone and permitting lactation indicates an evolutionary key role in calcium transfer across generations. Whether the RANKL/RANK pathway also controls epithelial cell growth in breast cancer has long remained unclear.

Recently, two groups have demonstrated that RANKL may be crucial for breast cancer development. Both groups employed a carcinogen-induced murine mammary tumor model supplemented with progesterone, which leads to the development of hormone receptor-positive mammary tumors $[8,9]$. Upon repeated administration of the carcinogen DMBA (7,12-dimethylbenz[ $\alpha]$ anthracene), along with the progestin medroxyprogesterone acetate, mice developed mammary tumors that were associated with increased RANKL expression in the progesterone receptor-positive epithelial component $[8,9]$ and expansion of the CD24-positive/highly CD49-positive cell fraction, a breast cancer stem cell population [8]. RANK-transgenic mice that overexpress the receptor of 
RANKL had an accelerated incidence of breast cancer after multiparity or medroxyprogesterone acetate treatment [9], whereas interruption of RANKL/RANK signaling attenuated progestin-driven breast cancer. The latter was achieved by two different approaches, the use of RANK ${ }^{\Delta \mathrm{mam}}$ mice, in which RANKL has no mammary receptor for its action [8], or application of RANK-Fc protein, which neutralises the effects of RANKL [9].

Taken together, the two studies clearly show that RANKL is involved in the development of carcinogeninduced mammary tumorigenesis in mice in the setting of progesterone treatment, and provided proof-ofconcept that blockade of RANKL may attenuate this process. These findings complement an earlier study from Josef Penninger's group where RANKL enhanced breast cancer cell migration into bone and spurred the development of bone metastases [10]. However, these findings are applicable only to the hormone receptorpositive variant of breast cancer, and not to hormone receptor-negative breast cancer, the more aggressive subtype. The first translational hurdle to be taken includes a careful characterization of the RANKL/RANK signaling pathway in the development of human breast cancer. If this is confirmed, one could envision that the RANK status may be determined from human breast cancer specimens, already a routine procedure for the estrogen receptor, the progesterone receptor, and HER2, the receptor for epidermal growth factor. Obviously, one could hypothesize that RANKL blockade with denosumab [6] may be used to prevent breast cancer. A long-term follow-up of the breast cancer incidence in women who had received denosumab for 3 years in the FREEDOM trial [6] may corroborate this hypothesis, and recent results from a study comparing denosumab with zoledronic acid in women with advanced breast cancer indicate superiority of denosumab in preventing skeletalrelated events [11]. A prospective study is currently assessing the effects of denosumab in women with early breast cancer (NCT01077154). This will reveal whether this promising news from basic research can live up to the great expectations.

\section{Abbreviations}

RANK, receptor activator of nuclear factor-KB; RANKL, receptor activator of nuclear factor-KB ligand.

\section{Competing interests}

$\mathrm{LCH}$ has received honoraria for lectures and serving in advisory boards from Merck, Novartis, Nycomed, and Amgen, and has received a research grant from Novartis. TDR has received unrestricted travel grants from Novartis and Amgen. $\mathrm{CH}$ has nothing to declare.

\section{Acknowledgments}

LCH's research program is supported by Deutsche Forschungsgemeinschaft Transregio 67 (project B2), HO 1875/12-1, HO 1875/13-1, and the Wilhelm Sander Foundation.

Authors' contributions

All authors analyzed the original studies and contributed to the final draft.

Author details

'Division of Endocrinology, Diabetes, and Bone Diseases, Department of Medicine III, Dresden Technical University Medical Center, Fetscherstr. 74, D-01307 Dresden, Germany. ${ }^{2}$ Center of Regenerative Therapies Dresden,

D-01307 Dresden, Germany. . ${ }^{3}$ epartment of Orthopedics, Dresden Technical University Medical Center, Fetscherstr. 74, D-01307 Dresden, Germany.

Published: 25 May 2011

\section{References}

1. Barrett-Connor E, Mosca L, Collins P, Geiger MJ, Grady D, Kornitzer M, McNabb MA, Wenger NK; Raloxifene Use for The Heart (RUTH) Trial Investigators: Effects of raloxifene on cardiovascular events and breast cancer in postmenopausal women. N Engl J Med 2006, 355:125-137.

2. Rennert G, Pinchev M, Rennert HS: Use of bisphosphonates and risk of postmenopausal breast cancer. J Clin Oncol 2010, 28:3577-3581.

3. Chlebowski RT, Chen Z, Cauley JA, Anderson G, Rodabough RJ, McTiernan A, Lane DS, Manson JE, Snetselaar L, Yasmeen S, O'Sullivan MJ, Safford M, Hendrix SL, Wallace RB: Oral bisphosphonate use and breast cancer incidence in postmenopausal women. J Clin Oncol 2010, 28:3582-3590.

4. Boyle WJ, Simonet WS, Lacey DL: Osteoclast differentiation and activation. Nature 2003, 423:337-342

5. Hofbauer LC, Schoppet M: Clinical implications of the osteoprotegerin/ RANKL/RANK system for bone and vascular diseases. JAMA 2004, 292:490-495.

6. Cummings SR, San Martin J, McClung MR, Siris ES, Eastell R, Reid IR, Delmas P, Zoog HB, Austin M, Wang A, Kutilek S, Adami S, Zanchetta J, Libanati C, Siddhanti S, Christiansen C, FREEDOM Trial: Denosumab for prevention of fractures in postmenopausal women with osteoporosis. N Eng/ J Med 2009, 361:756-765.

7. Fata JE, Kong YY, Li J, Sasaki T, Irie-Sasaki J, Moorehead RA, Elliott R, Scully S, Voura EB, Lacey DL, Boyle WJ, Khokha R, Penninger JM: The osteoclast differentiation factor osteoprotegerin-ligand is essential for mammary gland development. Cell 2000, 103:41-50.

8. Schramek D, Leibbrandt A, Sig IV, Kenner L, Pospisilik JA, Lee HJ, Hanada R, Joshi PA, Aliprantis A, Glimcher L, Pasparakis M, Khokha R, Ormandy CJ, Widschwendter M, Schett G, Penninger JM: Osteoclast differentiation factor RANKL controls development of progestin-driven mammary cancer. Nature 2010, 468:98-102.

9. Gonzalez-Suarez E, Jacob AP, Jones J, Miller R, Roudier-Meyer MP, Erwert R, Pinkas J, Branstetter D, Dougall WC: RANK ligand mediates progestininduced mammary epithelial proliferation and carcinogenesis. Nature 2010, 468:103-107.

10. Jones DH, Nakashima T, Sanchez OH, Kozieradzki I, Komarova SV, Sarosi I, Morony S, Rubin E, Sarao R, Hojilla CV, Komnenovic V, Kong YY, Schreiber M, Dixon SJ, Sims SM, Khokha R, Wada T, Penninger JM: Regulation of cancer cell migration and bone metastasis by RANKL. Nature 2006, 440:692-696.

11. Stopeck AT, Lipton A, Body JJ, Steger GG, Tonkin K, de Boer RH, Lichinitser M, Fujiwara Y, Yardley DA, Viniegra M, Fan M, Jiang Q, Dansey R, Jun S, Braun A: Denosumab compared with zoledronic acid for the treatment of bone metastases in patients with advanced breast cancer: a randomized, double- blind study. J Clin Oncol 2010, 28:5132-5139.

doi:10.1186/bcr2842

Cite this article as: Hofbauer LC, et al:: From bone to breast and back - the bone cytokine RANKL and breast cancer. Breast Cancer Research 2011, 13:107. 